DOI 10.37882/2223-2982.2020.06.02

\title{
СТРАТЕГИЯ ВЕРБАЛЬНОГО УСТРАШЕНИЯ В БРИТАНСКИХ СМИ
}

\section{THE STRATEGY OF VERBAL \\ SCARE-MONGERING IN BRITISH MEDIA}

M. Ageeva

Summary: This paper focuses on the strategy of scare-mongering in the British media through the use of hate speech. Particular attention is paid to the justification of the existence of a verbal expression of "the Russian threat" phenomenon. As a result of the study, one of the tactics that contribute to the active formation and scare-mongering of anti-Russian sentiments among modern British society was identified. The results can be used in further studies of the "hate speech" phenomenon and its verbal manipulative mechanisms.

Keywords: British media, Russian threat, verbal hate speech, the strategy of scare-mongering, distortion of proper names.
$\mathrm{B}$ современных условиях напряженных двусторонних отношений между Великобританией и Россией главным оружием для транслирования русофобных настроений стали СМИ. Средства массовой информации формируют «когнитивную карту мира» ("cognitive map of the world") [8, p. 21] и приобретают статус распространителя «эпидемии» вражды - идеологического инструмента, которым, на сегодняшний день, подвластно многое - вплоть до подчинения единой идее. В бесконечной информационной войне теряется смысл и важность произошедших событий. Выигравшей стороной становится та страна, журналисты которой первыми успели придать необходимую трактовку ситуации наиболее убедительным способом. Профессор Т.Г. Добросклонская отмечает, что «механизм функционирования СМИ предполагает не только и даже не столько отражение окружающей действительности, сколько, и это гораздо более важно, ее интерпретацию, комментарий, оценку, способствующие созданию определенного идеологического фона» [3, с. 19]. Таким образом, информационная функция СМИ уступает место функции убеждения, набирающей стремительную популярность даже в качественных источниках. Однако читатель, как и любой человек, не желает быть объектом манипуляций, именно поэтому «наибольшей эффективности функция убеждения достигает именно в скрытой форме» [6, р. 643].

Следует также обозначить один из ключевых элементов, способный обеспечить беспрекословную веру аудитории в предлагаемую журналистами интерпретацию событий - это страх. Являясь одной из сильнейших и при этом отрицательных эмоций, он лишает возможности здраво мыслить и рационально действовать, что суще-

\section{Агеева Мария Игоревна \\ Российский Университет Дружбы Народов (2. Москва) mariia.ageevaa@gmail.com}

Аннотация: В статье анализируется стратегия устрашения в британских СМИ посредством использования языка вражды. Особое внимание уделено обоснованию существования вербального выражения феномена «российская угроза». В результате исследования была определена одна из тактик, способствующая активному формированию и распространению анти-российских настроений среди современного британского общества. Полученные результаты могут быть использованы в дальнейших исследованиях феномена «языка вражды» и его вербальных манипулятивных механизмов.

Ключевые слова: британские СМИ, российская угроза, вербальный язык вражды, стратегия устрашения, искажение имен собственных.

ственно облегчает задачу манипулирования общественным сознанием.

Объектом исследования данной статьи является тактика обыгрывания и искажения имен собственных - России и действующего президента РФ - В.В. Путина. Исходя из классификации российского журналиста А.М. Верховского по степени «жесткости» («общественной опасности») подобная тактика относится к мягкому типу языка вражды и может быть расценена как попытка завуалированного «создания негативного образа» [1, с. 14]. Анализ был проведён на основе британских журналов о политике, культуре и текущих событиях: "The Economist", "The Week", "The Independent", "The Guardian", "Daily Mail”, "Bloomberg", "The Sun", "ВBC". Исходя из обнаруженных примеров, можно заключить, что журналисты прибегают к искажению имен собственных с помощью приемов пре - и постмодификаторов, языковой контаминации, суффиксации, игры слов, а также лексико-семантической трансформации и метафоризации.

Премодификатор как синтаксическая единица уточняет значение следующего за ним слова в наиболее сжатой форме («с использованием меньшего количества слов» [5, с. 588], нежели в постмодификаторе), называя при этом его «свойство, качество или характеристику» [9]. Так, в примерах (1-3) авторы раскрывают идею о властолюбивом и жестком правителе России, власть которого безгранична, а значит, представляет потенциальную опасность:

(1) Hard man Putin (Bloomberg, 19.07.2019) - Суровый Путин

(2) 'Power-hungry' Putin reveals he intends to cling on 
to office - by becoming Russia's next prime minister (Daily Mail, 10.10.2007) - Властолюбивый Путин раскрывает свои намерения задержаться на посту, став следующим премьер-министром

(3) It was a pyramid - with an all-powerful Putin at the top, and everyone down below following orders (BВC, 10.11.2011) - Это была пирамида - с всемогущим Путиным на вершине и всеми остальными внизу, исполняющими приказы

В данных случаях, стратегия устрашения достигается при помощи многократного повторения конструкта "power" (власть). Говоря о суровости президента, олицетворяющего Россию ("hard man") журналисты подчеркивают необходимость осторожного отношения к гражданам страны, избирающим своего лидера на протяжении 12 лет (что говорит о доверии и одобрении действий президента как внутри страны, так и за ее пределами).

Постмодификаторы аналогичным образом служат для уточнения значения главного элемента ("the head") [5, с. 588], однако в нижеприведенных примерах образ раскрывается благодаря семам с более очевидным смыслом "terrible", "danger", "gangster":

(4) Putin the terrible (The Week, 24.03.2018) - Путин Грозный

(5) VLAD DANGER (The Sun, 24.11.2018) - ВЛАДOПACHOCTЬ.

(6) Putin the cyber gangster (Daily Mail, 5.10.2018) Путин - кибер-гангстер

В примере (4) журналисты используют аналогию с Иваном Грозным - правителем Руси с 1547 по 1584 годы, который запомнился русской истории как один из самых жестоких царей России. Данная метонимия ("the terrible") позволяет автору привнести в образ нынешнего президента черты кровожадности его предшественника. С помощью заглавных букв в примере (5) издатели газеты "The Sun" предприняли попытку привлечь внимание широкого круга читателей к угрозе, исходящей от президента РФ, подкрепляя заголовок существительным "threat" - угроза, а также заявлением главнокомандующего британской армии Марка Смита о том, что Россия представляет гораздо большую опасность для национальной безопасности Великобритании, чем запрещенная на территории РФ террористическая организация "Исламское государство» ("Russia is a bigger threat to UK security than ISIS, warns British Army chief" - The Sun, 24.11.2018). Слова Смита цитирует и газета The Guardian в номере от 24 ноября 2018 года. Шпионаж и кибератаки на территории Великобритании последние несколько лет приписывают исключительно России. Так, например, в 2016 году член парламента Бен Брэдшоу заявил, что Россия вмешалась в кампанию референдума по выходу Великобритании из Европейского союза: “Not only their [Russian] interference, now proven, in the American presidential campaign, [but] probably in our referendum last year. We don't have the evidence for that yet. But I think it's highly probable" (The Independent, 13.12.2016) - «Они [Россия] вмешались не только в американскую избирательную кампанию, что уже доказано, но, вероятно и в наш референдум в прошлом году. И хотя у нас пока нет доказательств, я полагаю с высокой долей вероятности, что это происходило». В примере (6) журналисты объединили сразу две идеи: о кибершпионаже, к которому причастен Владимир Путин, а также о его связи с преступностью, что автоматически приумножает анти-российские настроения среди читателей.

Журналисты газеты “The Sun" использовали более лаконичный способ передачи аналогичной примеру (6) информации (не потеряв при этом имплицитности и интенции) - так, в примерах (7-8) была применена языковая контаминация, которую С. И. Ожегов определяет как «возникновение нового выражения, слова, формы путем объединения элементов двух выражений или форм» [4, c.291]:

(7) The Vladfather (The Sun, 5.10.2018) - «Крестный отец» Путин

(8) Vladiator Putin declares liberal values are 'obsolete' and dismisses Skripal poisoning as a 'fuss' that's 'not worth five pounds' (The Sun, 28.06.2019) - Владиатор Путин заявляет, что либеральные ценности «устарели», а отравление Скрипаля - «суета», которая «копейки не стоит»

Пример (7) демонстрирует слияние имени "Vlad" (coкращенное от Владимир) и слова "Godfather" (крестный отец) - смысл последнего в отсылке к экранизации знаменитой криминальной саги Ф.Ф. Копполы с одноименным названием, повествующей о мафиозной семье и преступном мире. Связывая имя президента РФ с подобным символом, журналисты не оставляют выбора адресату - его подсознание начинает сопоставлять образы. Истоки подобного представления обнаружены в журнале "The Week" от 3 марта 2012 года, где В.В. Путин изображен в образе главного героя - крестного отца. В примере (8) имя президента "Vlad" журналисты интегрируют в слово "Gladiator" (гладиатор) от латинского "gladius" «меч», приписывая ему качества воина и бойца.

Не менее эффективным способом манипулирования общественным сознанием является создание неологизмов с помощью разнообразных суффиксов. Так, примеры (8-10) показывают, как при помощи суффикса "ism" - со значением «учения, политического движения», возникает термин в противопоставление западным ценностям:

(8) Will Putinism see the end of Putin? (The Guardian, 27.02.2012) - Застанет ли Путинизм конец правления Путина?

(9) 'Putinism', a new creed for Europe's tough men - 
«Путинизм», новое кредо для жестких мужчин в Европе (The Independent, 3.08.2014)

(10) Putinism (The Economist, 22.10.2016) - Путинизм (на обложке выпуска)

Выстроенная власть вокруг одного человека быстро обрела определение среди зарубежных исследователей и приобрела негативную семантику: "Putinism is a form of autocracy that is conservative, populist, and personalistic" [7, p.61] - Путинизм - это форма самодержавия, которая является консервативной, популистской и персонифицированной. Исследователи Я. Грегор и Э. Томашкова отмечают, что «неолексемы, образованные от фамилии общественного деятеля при помощи суффикса -изм-, очень распространены в современном политическом дискурсе (например, тэтчеризм, голлизм, путинизм, трампизм)» [2, с. 1166].

Крылатое выражение, вызывающее прямые ассоциации с гостеприимной Россией "From Russia with love" подверглось негативизации значения при помощи лексикосемантической трансформации:

(11) From Russia without love? (BBC, 22.11.2018) - Из России с нелюбовью?

(12) FROM RUSSIA WITH DRUGS (The Sun, 5.12.2017) - Из России с наркотиками

В примере (11) журналисты ставят под вопрос дружелюбие России, в то время как пример (12) утверждает точку зрения представителей британских СМИ о массо- вом и систематическом использовании запрещенных препаратов (допинга) российскими спортсменами для достижения личной выгоды.

Метафоризация, основанная на игре созвучных слов, также может быть использована в качестве крайне завуалированной стратегии устрашения:

(13) Vlad to see you (Daily Mail, 29.08.2019)

Изменение лексемы "glad" на "vlad" в указанном примере не представляет на первый взгляд негативного подтекста, поскольку денотация (явное значение) второго слова - всего лишь имя (Vlad - сокращенный вариант имени Владимир, часто употребляемый в британских СМИ). Что касается коннотации, то примеры $(1,2,4,5,8)$ доказывают, что имя Путина часто ассоциируется с опасностью и недружелюбием, из чего можно заключить, что слова "glad" и "vlad" являются авторскими антонимами.

Проведенное исследование показало, что стратегию устрашения в британских СМИ можно раскрыть и обозначить с помощью разных языковых средств - пре- и постмодификаторов, игры слов, языковой контаминации, лексико-семантической трансформации, метафоризации и суффиксации, каждое из которых привносит свой оттенок значения и влияет на формирование языка вражды в целом среди британского современного общества. Регулярное использование негативных контекстов в адрес России и ее президента способствует закреплению образа перманентной «угрозы».

\section{ЛИТЕРАТУРА}

1. Верховский А.М. Язык вражды против общества. - М.: Информационно-аналитический центр «Сова», 2007. - 259с.

2. Грегор Я., Томашкова Е. Как назвать Ангелу Меркель: неологизмы немецкого политического дискурса в иноязычных CMИ / Quaestio Rossica. № 4. 2018. c. $1160-1173$

3. Добросклонская Т.Г. Методы анализа видео-вербальных текстов / Медиалингвистика. №2. 2016. - с. 13-24

4. Ожегов С.И., Шведова Н.Ю. Толковый словарь русского языка: 80000 слов и фразеологических выражений / Российская академия наук. Институт русского языка им. В.В. Виноградова. - 4-е изд., дополненное. - М.: 000 «А ТЕМП», 2006. - 944 с.

5. Bieber D. Longman Student Grammar of Spoken \& Written English. Pearson. -613 p.

6. Ejupi V. The mass media and persuasion. 2014. - p. 636-646

7. Fish M. What is Putinism? Journal of Democracy. 2017. - $28 \mathrm{p}$.

8. Roich F. Media and crime in Argentina: punitive discourse during the 1990s. London: Palgrave Macmillan, 2017. - 248 p.

9. Викиучебник английского языка EnGramm. Режим доступа URL: https://engramm.su/grammar/modifier (дата обращения 29.03.2020)

10. ВBC. Режим доступа URL: https://www.bbc.com/news/world-europe-16107101 (дата обращения 10.04.2020)

11. ВВС. Режим доступа URL: https://www.bbc.com/news/av/newsbeat-46305456/from-russia-without-love-a-newsbeat-documentary (дата обращения 10.04.2020)

12. Bloomberg. Режим доступа URL: https://www.bloomberg.com/news/articles/2019-07-19/hard-man-putin-may-be-showing-softer-side-to-russia-s-neighbors (дата обращения 11.03.2020)

13. Daily Mail. Режим доступа URL: https://www.dailymail.co.uk/news/article-485070/Power-hungry-Putin-reveals-intends-cling-office--Russias-prime-minister. $\mathrm{html}$ (дата обращения 28.03.2020)

14. Daily Mail. Режим доступа URL: https://www.dailymail.co.uk/video/news/video-1995382/Video-Vlad-lady-serves-Putin-ice-cream-two-years-apart.html (дата обращения 28.03.2020)

15. Daily Mail. Режим доступа URL: https://twitter.com/BBCNews/status/1047964980744781824/photo/1 (дата обращения 29.03.2020) 
16. The Economist. Режим доступа URL: https://www.economist.com/printedition/2016-10-22 (дата обращения 15.03.2020)

17. The Guardian. Режим доступа URL: https://www.theguardian.com/world/2012/feb/27/vladimir-putin-profile-putinism (дата 0бращения 25.03.2020)

18. The Guardian. Режим доступа URL: https://www.theguardian.com/uk-news/2018/nov/24/russia-poses-greater-threat-than-isis-new-british-army-chief-warns (дата обращения 1.03.2020)

19. The Independent. Режим доступа URL:https://www.independent.co.uk/news/uk/politics/russian-interference-brexit-highly-probable-referendum-hackingputin-a7472706.html (дата обращения 2.04.2020)

20. The Independent. Режим доступа URL: https://www.independent.co.uk/news/world/europe/putinism-a-new-creed-for-europes-tough-men-9644628.html (дата обращения 16.03.2020)

21. The Sun. Режим доступа URL: https://www.thesun.co.uk/news/7418650/vladimir-putin-speech-language-slang-gangster/ (дата 0бращения 10.04.2020)

22. The Sun. Режим доступа URL: https://www.thesun.co.uk/news/9391353/vladimir-putin-liberal-obsolete-skripal-poisoning-fuss/ (дата обращения 10.04.2020)

23. The Sun. Режим доступа URL: https://www.thesun.co.uk/sport/5074499/russia-banned-winter-olympic-games-doping/ (дата обращения 10.04.2020)

24. The Week. Режим доступа URL: https://downmagaz.com/business_magazine_economics/8172-the-week-uk-03-march-2012.html (дата обращения 7.04.2020)

25. The Week. Режим доступа URL: https://photoshare.ru/photo14833196.html (дата обращения 7.04.2020)

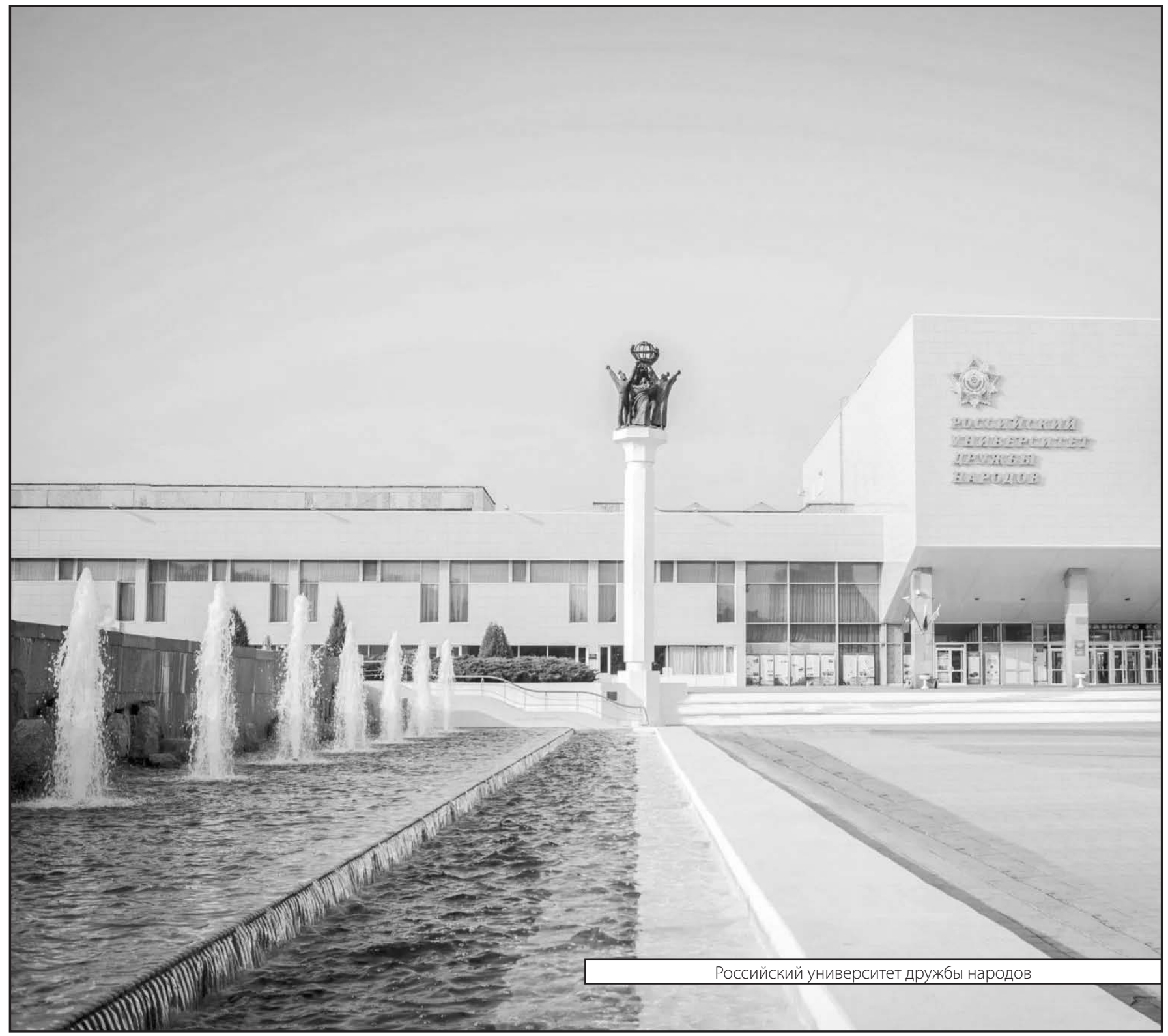

